\title{
A dinâmica territorial dos deslocamentos pendulares na área urbana funcional de Santa Maria-RS, Brasil
}

\author{
Rogério Leandro Lima da Silveira ${ }^{1}$ \\ Carolina Rezende Faccin ${ }^{2}$ \\ Débora Frantz Krug ${ }^{3}$ \\ Nicolas Billig de Giacometti ${ }^{4}$
}

\begin{abstract}
Resumo
Os estudos sobre desenvolvimento urbano e regional e planejamento territorial têm valorizado o policentrismo como recurso metodológico na análise da dinâmica territorial na escala regional. Na região Central do Rio Grande do Sul, a cidade média de Santa Maria apresenta centralidade econômica e desempenha importante papel de intermediação e polarização dos principais fluxos no território regional. Objetiva-se analisar a constituição e dinâmica da área urbana funcional (FUA) de Santa Maria, e verificar as caraterísticas socioespaciais dos deslocamentos para trabalho e estudo entre as cidades da região e possíveis reflexos no desenvolvimento urbano e regional. Metodologicamente, ancora-se no referencial teórico sobre policentrismo urbano, cidades médias e sua relação com o desenvolvimento regional. Utiliza-se microdados sobre deslocamentos pendulares, e dados sobre a urbanização e economia municipais, do Censo Demográfico de 2010 do IBGE. Os resultados apontam que na FUA de Santa Maria predominam fluxos pendulares monodirecionais, e os de maior intensidade se destinam para Santa Maria. A centralidade econômica e de serviços de Santa Maria, a predominância da atividade primária nos demais municípios, e a acessibilidade e proximidade espacial entre a cidade média e os demais municípios da FUA, são variáveis relevantes na atual dinâmica territorial da região central do Rio Grande do Sul.
\end{abstract}

Palavras-chave: Áreas Urbanas Funcionais. Cidade Média. Dinâmica Urbana e Regional. Deslocamentos Pendulares. Região Central do Rio Grande do Sul.

\section{The territorial dynamics of commuting in the functional urban area of Santa Maria - Rio Grande do Sul-Brazil}

\begin{abstract}
Studies on urban and regional development and territorial planning have valued polycentrism as a methodological resource in the analysis of territorial dynamics at regional scale. In the Central region of Rio Grande do Sul, the medium-sized city of Santa Maria has economic centrality and plays an important role in intermediating and polarizing the main flows in the regional territory. The objective is to analyze the constitution and dynamics of the functional urban area (FUA) of Santa Maria, and to verify the socio-spatial characteristics of the displacements for work and study between the cities of the region and possible reflexes in the urban and regional development. Methodologically, it is anchored in the theoretical reference on urban polycentrism, medium cities and their relationship with regional development. It uses microdata on commuting, and data on urbanization and municipal economy from the 2010 IBGE Demographic Census. The results show that in the FUA of Santa Maria monodirectional commuter flows predominate, and those of greater intensity are destined for Santa Maria. The economic and service centrality of Santa Maria, the predominance of primary activity in the other municipalities, and the accessibility and

\footnotetext{
${ }^{1}$ Doutorado em Geografia. Professor do Programa de Pós-Graduação em Desenvolvimento Regional da Universidade de Santa Cruz do Sul (UNISC). https://orcid.org/0000-0003-1003-9470 Email: rlls@unisc.br

2 Arquiteta e Urbanista. Mestranda em Planejamento Urbano e Regional no Programa de Pós-Graduação em Planejamento Urbano e Regional (UFRGS). Email: faccincarolina@gmail.com

${ }^{3}$ Arquiteta e Urbanista. Email: krugdebora@gmail.com

${ }^{4}$ Arquiteto e Urbanista. Mestrando em Planejamento Urbano e Regional no Programa de Pós-Graduação em Planejamento Urbano e Regional (UFRGS).Email: nbgiacometti@gmail.com
} 
spatial proximity between the middle city and the other municipalities of the FUA, are relevant variables in the current territorial dynamics of central region Rio Grande do Sul.

Keywords: Functional Urban Areas. Medium-sized city. Urban and regional dynamics. Commuting. Central region of Rio Grande do Sul.

\section{Introdução}

No atual estágio da economia capitalista, os territórios, em suas diferentes escalas espaciais, têm apresentado crescente especialização e intensa mobilidade geográfica de fluxos de diferentes tipos. Desde os fluxos de capitais, passando pelos de mercadorias e informações, até os fluxos de pessoas, entre os quais os deslocamentos pendulares para trabalho. Tais fluxos tem levado ao aumento das disparidades territoriais, da fragmentação espacial, ao mesmo tempo em que promovem interações e interrelações entre as cidades, e entre as cidades e as regiões onde estão localizadas. (SANTOS, 2000; SILVEIRA et al, 2017).

Observamos também nesse período uma intensificação do processo de urbanização em escala mundial, em que além do já destacado crescimento das metrópoles e do papel de comando que exercem na economia global (SASSEN, 2010; BRENNER, 2018), há também um crescente protagonismo das chamadas cidades médias ou intermédias nos processos de desenvolvimento urbano e regional (LLOP, USÓN, 2012; SPÓSITO, SILVA, 2017).

O presente artigo busca contribuir com a reflexão teórica e metodológica sobre o uso das noções de cidade média e de policentrismo, esta última, através da constituição de áreas urbanas funcionais, na análise da dinâmica urbana e regional e do desenvolvimento territorial, na escala regional. Importa também verificar, com base na compreensão sobre a constituição e a dinâmica da área urbana funcional, como as cidades médias se relacionam com suas regiões, como exercem sua centralidade e influenciam o processo de desenvolvimento regional.

O recorte empírico escolhido para a análise é a região Central, do estado do Rio Grande do Sul, localizado no sul do Brasil. A Região Central é uma das vinte oito regiões de planejamento do estado do Rio Grande do Sul, constituídas a partir de 1990, quando da institucionalização dos Conselhos Regionais de Desenvolvimento (COREDEs). O território da região Central é constituído por dezenove municípios que integram o COREDE Central, e a sede administrativa se localiza na cidade média de Santa Maria.

Metodologicamente busca-se caracterizar o território da região Central, sua estrutura urbana e a centralidade urbana da cidade média de Santa Maria, com base no levantamento de dados secundários dos Censos Demográficos de 2000 e 2010, do estudo Regiões de Influência das Cidades (REGIC) de 2007, e do sistema de informações IBGE Cidades, todos do IBGE; e do 
Plano Estratégico de Desenvolvimento Regional, do Conselho Regional de Desenvolvimento da Região Central (2015-2030). Os dados depois de levantados foram sistematizados e serviram de base para a confecção de mapas temáticos e de fluxos, através do software QGIS e Illustrator, que permitiram identificar e melhor analisar as áreas urbanas funcionai s existentes no território, sua configuração espacial, e os principais fluxos e interações socioespaciais existentes entre as cidades da região, decorrentes dos movimentos pendulares para trabalho e estudo.

O objetivo é analisar a centralidade da cidade média de Santa Maria na Região Central, através desse fluxo pendular de pessoas. A cidade de Santa Maria desempenha importante papel de centro regional atraindo os deslocamentos pendulares para trabalho e estudo e polarizando o espaço geográfico regional. Assim, se buscou compreender melhor a relação entre a configuração espacial e o funcionamento das áreas urbanas funcionais e sua relação com a dinâmica de desenvolvimento territorial nesta região.

O trabalho está estruturado em três tópicos. No primeiro, realiza-se uma breve revisão teórica dos conceitos de cidade média, policentrismo funcional e área urbana funcional (FUA) destacando sua importância metodológica e analítica para a compreensão da dinâmica territorial, notadamente na escala urbana e regional. No segundo tópico, se faz uma breve caracterização territorial, demográfica e econômica da Região Central, da centralidade regional da cidade média de Santa Maria e da configuração espacial da FUA de Santa Maria. No terceiro e último tópico, se analisa alguns aspectos quanto à origem, destino, e intensidade dos fluxos de deslocamento para trabalho no território regional, buscando-se compreender melhor as características desses fluxos pendulares no interior da FUA, e sua importância para a compreensão da centralidade da cidade média de Santa Maria, e da dinâmica de desenvolvimento regional.

\section{Cidade Média, Policentrismo e FUAs: Elementos para a compreensão da dinâmica territorial} urbana e regional

O conceito e definição de cidade média estão em construção. Não há uma definição consensual a respeito, dada a especificidade e diversidade da classificação e tipologia urbana empregada em cada país. Ora vamos ter a sua definição baseada no critério demográfico, ora pela centralidade e funções urbanas das cidades (SPOSITO, 2007). Além disso, os critérios utilizados para sua definição dependem dos objetivos dos especialistas na análise e implementação das políticas públicas específicas. 
De todo modo, pensamos que sua definição não deva estar apenas vinculada ao tamanho da sua população, como faz o IBGE ao classificar como média as cidades que apresentam entre 100 e 500 mil habitantes. Embora o tamanho demográfico seja um dado importante a ser considerado na definição de cidade média pensamos que também se deva considerar o papel ou função que a cidade desempenha regionalmente, e conteúdo e a dinâmica da relação que a cidade estabelece com a região na qual está localizada.

A noção de cidade média que pensamos mais adequada, e que utilizamos neste trabalho, é a que corresponde às cidades que além de possuírem um contingente demográfico expressivo, no contexto regional, também apresentam uma concentração e centralização econômicas e uma consolidada função de intermediação econômica e de serviços públicos, e de fluxos diversos, entre seu hinterland e a metrópole (LLOP e USON, 2012). Além disso é preciso também considerar os níveis das atividades econômicas resultantes da confluência dos sistemas de transporte e logística, e a reconfiguração espacial advinda da incorporação de novas atividades ao setor agropecuário que, por sua vez, redefinem a indústria, o comércio e os serviços, e as funções e centralidade urbana das cidades médias. (SPOSITO, 2007; SANTOS e SILVEIRA, 2001).

A reflexão sobre as cidades médias, as suas áreas urbanas funcionais ou functional urban areas (FUAs) em sua relação com a dinâmica territorial, sobretudo na escala regional, nos remete à noção de policentrismo ou de policentralidade. Tal noção, de modo simplificado, está relacionada a existência de um conjunto de centros urbanos, com diferentes funções econômicas e de gestão, com distintas capacidades e condições de centralidade urbana, que se interrelacionam num dado espaço regional. e que ao mesmo tempo que refletem o processo de desenvolvimento econômico regional, igualmente condicionam a dinâmica de organização espacial e as relações intra e interregionais no território (CATTAN, 2007 e DAVOUDI, 2003).

No campo dos estudos urbanos e do planejamento urbano e regional a noção de policentrismo não é nova. Davoudi (2003) nos lembra que ela surge inicialmente no começo da década de 1920, com os estudos de Burgess, no âmbito da Escola de Chicago. Posteriormente, a partir de 1970, o conceito ganha expressão com os estudos de Brian Berry sobre o sistema urbano americano, através da análise dos movimentos pendulares para o trabalho, e da configuração de regiões urbanas.

Mas foi principalmente no começo deste século, a partir dos trabalhos realizados pelo ESPON (European Observation Network for Territorial Development and Cohesion), no contexto da formulação e implementação das bases conceituais e operacionais da política pública de 
desenvolvimento territorial europeia, que o policentrismo tem ganhado atenção, tanto no âmbito dos organismos estatais quanto no da academia.

Nesse trabalho, se utiliza o policentrismo como recurso metodológico para compreender a dinâmica territorial regional (HALL, 2007; DAVOUDI, 2007). O que interessa é abordar o potencial metodológico e analítico do conceito de FUA para os estudos urbanos e regionais, notadamente em relação ao seu uso para a análise e compreensão da centralidade das cidades médias e do desenvolvimento da dinâmica territorial, em contextos regionais de formações socioespaciais periféricas, e polarizadas por cidades médias com diferentes tamanhos demográficos (SILVEIRA et al., 2016; SÝKORA, MULÍČEK, 2009).

Os conceitos de FUA e de rede urbana, são alguns dos principais elementos que estruturam a agenda de pesquisa atual sobre o policentrismo e sua relação com o espaço regional (CATTAN, 2007). Eles auxiliam na análise da dimensão territorial da divisão do trabalho, e dos processos de interação socioespacial e das interrelações entre as cidades de uma dada região, ao possibilitar uma melhor identificação e entendimento das configurações, das características e dos conteúdos de alguns dos principais fluxos que circulam no território regional, como os fluxos pendulares, e os fluxos de gestão pública e privada. Permitem igualmente, verificar os diferentes níveis de centralidade urbana existentes, as interrelações entre as cidades, e identificar as suas áreas de influência no território regional.

A área urbana funcional é um tipo de região funcional. Como tal ela é uma dada área territorial caracterizada por apresentar uma alta frequência de interações econômicas como o comércio de bens e serviços, deslocamentos para trabalho e compras domésticas realizadas no interior da região. Ela é caracterizada pela aglomeração de atividades e por sua infraestrutura intrarregional de transportes, que facilite ampla mobilidade de pessoas, produtos e insumos dentro das suas fronteiras (KARLSSON, OLSSON, 2006).

A FUA tem se tornado um importante nível funcional do sistema urbano e regional, pois, atualmente os núcleos das áreas urbanas e suas áreas marginais têm formado regiões funcionais cada vez mais integradas e entrelaçadas, em razão dos diversos, crescentes e multidirecionais fluxos de pessoas que se deslocam no espaço geográfico para o mercado de trabalho e para acessar a educação. A FUA é um importante pré-requisito e ferramenta para uma análise das tendências urbanas e regionais, ao possibilitar melhor compreensão da dinâmica interna de uma dada região através de suas relações funcionais intrarregionais (ANTIKAINEN, 2005). 


\section{Caracterização territorial da Região Central e da centralidade da cidade média de Santa Maria}

A Região Central está localizada no centro ocidental do Estado do Rio Grande do Sul, e é composta por dezenove municípios que integram o COREDE Central. Dentre os municípios, está a cidade média de Santa Maria, polo econômico e atrativo de toda a região (Figura 1).

Figura 1 - Região Central: Mapa de localização e configuração espacial

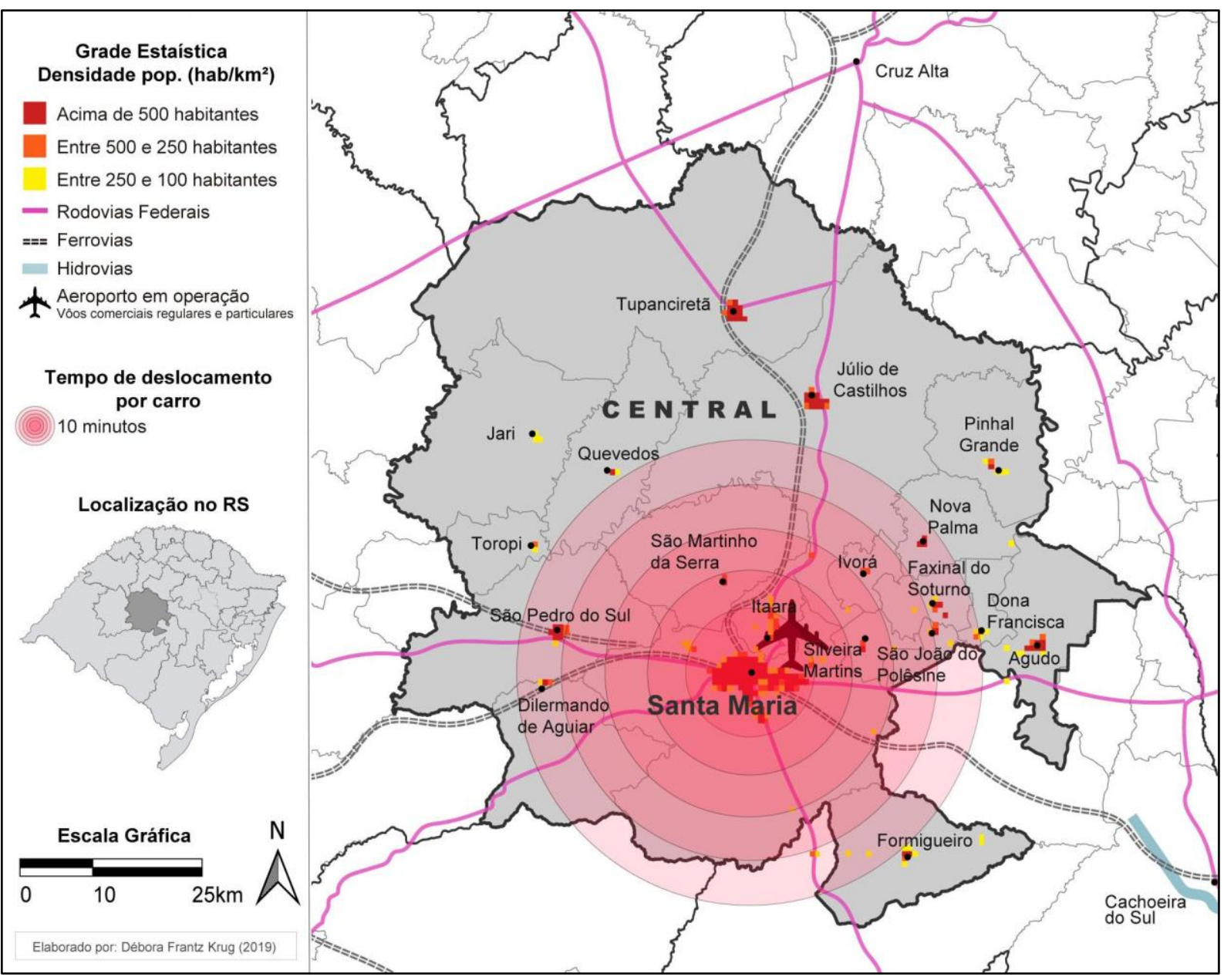

Elaboração: Débora Frantz Krug (2019) com base em IBGE (2010).

Essa região se caracteriza pela predominância da atividade agropecuária, com destaque para a produção e beneficiamento industrial do arroz, do trigo e da soja, além da criação de gado bovino. A região é polarizada pela cidade média de Santa Maria, capital regional de acordo com a hierarquia urbana definida pelo estudo das Regiões de Influência das Cidades - REGIC 2007, elaborado pelo IBGE (IBGE, 2008).

Santa Maria é a cidade com maior contingente demográfico, com expressiva centralidade urbana, através de uma economia urbana baseada sobretudo nas atividades comerciais e serviços, e que polariza e influencia o conjunto da região. A centralidade de Santa Maria também 
é exercida através da oferta de ensino superior através da UFSM, bem como de outras universidades e faculdades nela sediadas. Uma outra atividade que reforça essa centralidade é a militar, através da existência na cidade de inúmeras instalações do exército e da aeronáutica.

A configuração espacial da região evidencia que há pelo menos dois conjuntos de municípios quanto a dimensão territorial, resultantes de diferenciadas estruturas fundiárias. De um lado, há os municípios a leste, como Agudo, Dona Francisca, Silveira Martins, São João do Polêsine Nova Palma e Pinhal Grande que apresentam pequena área territorial fruto de um intenso processo de fragmentação e parcelamento de propriedades rurais, advindos da busca de reprodução social pelas sucessivas gerações das famílias que colonizaram essa região, bem como resultam do processo de emancipações municipais que ocorreram sobretudo a partir dos anos 1980. De outro lado, ao norte da região, há a presença de municípios com médias e grandes áreas territoriais, advindas de uma estrutura fundiária caracterizada pela média e grande propriedade, como são os casos de Tupanciretã e Júlio de Castilhos, herdeiros de uma dinâmica de formação territorial engendrada desde os tempos coloniais e da república velha.

Outro aspecto a ser destacado na configuração territorial e urbana da região é sua estrutura urbana. Com base na Tabela 1, observa-se que há o predomínio de pequenas cidades (14 cidades, de 19) com até 5 mil habitantes. Elas representam 73,68\% do total das cidades da rede urbana regional. Apenas a cidade média de Santa Maria possui mais de 100 mil habitantes residentes em área urbana, sendo que, em 2010, esse montante era de 248 mil habitantes (IBGE, 2010).

Tabela 1 - Região Central: № de cidades por faixa de população urbana - 2010

\begin{tabular}{cccccc}
\hline $\begin{array}{c}\text { Até } 5 \text { mil } \\
\text { habitantes. }\end{array}$ & $\begin{array}{c}\text { De 5.001 a 10.000 } \\
\text { hab. }\end{array}$ & $\begin{array}{c}10.001 \text { a 20.000 } \\
\text { hab. }\end{array}$ & $\begin{array}{c}20.001 \text { a } 50.000 \\
\text { hab. }\end{array}$ & $\begin{array}{c}50.001 \text { a } 100.000 \\
\text { hab. }\end{array}$ & $\begin{array}{c}\text { Mais de } 100.001 \\
\text { hab. }\end{array}$ \\
\hline 14 & 1 & 3 & 0 & 0 & 1 \\
\hline
\end{tabular}

Elaboração: Nicolas Giacometti e Carolina Faccin (2019) com base em IBGE (2010).

Os dados apresentados na Tabela 1 mostram que a estrutura urbana regional evidencia uma distribuição desigual da população urbana entre as cidades da região, e uma expressiva concentração da população urbana regional em Santa Maria. A maior centralidade e dinamismo econômico dessa cidade atrai a população, os investimentos e a renda excedente da região, ao mesmo tempo que ela comanda e intermedia os diferentes fluxos que animam a rede urbana regional. 
Como condição e reflexo dessa dinâmica regional o sistema viário regional, representado na Figura 1, apresenta duas importantes rodovias. A rodovia federal BR-158 liga as partes norte e sul da região, articulando a cidade de Santa Maria com a de Cruz Alta, importante centro agroindustrial da soja e do trigo da região do Alto Jacuí. Já a rodovia estadual RST-287 cruza a região no sentido oeste-leste, ligando a região Central ao noroeste do estado e à região fronteiriça das Missões, bem como, à leste, ligando à capital do Estado e à região metropolitana de Porto Alegre. Observa-se também que, no sistema viário regional, a cidade de Santa Maria desempenha importante papel como entroncamento rodoferroviário que permite o escoamento da produção agrícola regional para as plantas de processamento e beneficiamento industrial localizadas na região, mas também para o porto de Rio Grande.

Em relação aos aspectos demográficos, a região possui uma população de 326.486 habitantes, correspondendo a 3,58\% da população gaúcha. Aproximadamente $83 \%$ da população regional residem na área urbana, e 17\% na área rural. Entre 2000 e 2010, a região apresentou uma taxa de crescimento demográfico de $0,37 \%$ ao ano, e os municípios com maior taxa de crescimento foram Itaara, com 0,91\%, e Santa Maria, com 0,69\% (IBGE, 2000; 2010).

Dos 19 municípios da região, 11 deles possuem a maior parte da população residindo na área rural, com taxas de urbanização inferior a 50\%, refletindo a predominância nestes municípios das pequenas e médias propriedades agrícolas, com a presença da agricultura familiar e do agronegócio. Nesses municípios temos pequenas cidades que exercem basicamente a função de gestão municipal e centros de escoamento da produção agrícola local, com limitada oferta dos serviços básicos e capacidade de geração de emprego.

Os municípios com maior taxa de urbanização são Santa Maria com 95,1\% e Júlio de Castilhos com 82,3\%. Na Tabela 2 observamos o quão representativo é o município de Santa Maria em relação à população urbana e população total da região Central. Santa Maria respondia, em 2010 , por $76,06 \%$ da população urbana e por $66,65 \%$ da população total da região Central, evidenciando a concentração nessa cidade média de expressivo contingente da população regional.

Tabela 2 - Região Central e município de Santa Maria: População urbana, população total e taxa de urbanização 2000 e 2010

\begin{tabular}{l|cccccc}
\hline \multicolumn{1}{c|}{ Unidade Espacial } & \multicolumn{2}{c}{ População urbana } & \multicolumn{2}{c}{ População total } & \multicolumn{2}{c}{ Taxa urbanização } \\
\hline \multirow{2}{*}{ Santa Maria } & $\mathbf{2 0 0 0}$ & $\mathbf{2 0 1 0}$ & $\mathbf{2 0 0 0}$ & $\mathbf{2 0 1 0}$ & $\mathbf{2 0 0 0}$ & $\mathbf{2 0 1 0}$ \\
\cline { 2 - 7 } & 230.696 & 248.347 & 243.611 & 261.031 & $94,70 \%$ & $95,14 \%$ \\
\hline Demais municípios & 73.606 & 78.139 & 133.658 & 130.602 & $55,00 \%$ & $60,00 \%$ \\
\hline
\end{tabular}




\begin{tabular}{l|cccccc} 
Região Central & 304.302 & 326.486 & 377.269 & 391.633 & $80,00 \%$ & $83,00 \%$ \\
\hline Rio Grande do Sul & 8.317 .984 & 9.100 .291 & 10.187 .798 & 10.693 .929 & $81,00 \%$ & $85,00 \%$ \\
\hline
\end{tabular}

Elaboração: Nicolas Giacometti e Carolina Faccin (2019) com base em IBGE (2010).

Verificamos ainda que a cidade média de Santa Maria apresenta ampliação do processo de urbanização entre 2000 e 2010, de 94,70\% para 95,14\%, consolidando sua posição de centro urbano mais populoso da região Central, bem como apresentando uma taxa de urbanização superior à verificada na região e no estado.

Em relação à economia regional assinala-se que o Produto Interno Bruto em 2010 foi de R\$ 16,7 bilhões, correspondendo a 6\% do PIB total gaúcho (SEPLAG \& DEPLAN, 2015). Na Figura 2 podemos verificar a distribuição do PIB per capita nos municípios que integram a região, e assim verificar o quão desigual é esse desempenho no território regional. Enquanto na parte central e norte da região preponderam PIB per capita mais elevados, entre $\mathrm{R} \$ 40.000,00$ e mais de $\mathrm{R} \$$ 70.000,00, com destaque para o município de Pinhal Grande, na parte sul, encontram-se os municípios com menor desempenho, entre os quais São Pedro do Sul, Itaara, Silveira Martins e Dona Francisca com PIB per capita menores de R\$1 19.999,00 (IBGE, 2017).

Complementarmente, os dados da distribuição setorial do Valor Adicionado Bruto (VAB) setorial, do ano de 2010, nos municípios do conjunto da região central apontam que há uma menor participação do setor da agropecuária na produção regional, com cerca de 10,2\%, seguida pelo setor industrial, com $14,7 \%$. Já o setor de serviços corresponde a $75 \%$ do VAB da região Central (IBGE, 2017). Os dados relativos ao VAB dos municípios da região indicam que para muitos municípios há uma grande dependência econômica dos recursos advindos dos setores de comércio e serviços e da administração pública, no qual estão incluídos os repasses constitucionais (Fundo de Participação dos Municípios) e os recursos relativos à aposentadorias rurais e urbanas, Benefício de Prestação Continuada, Bolsa Família entre outros. Esses são os casos, por exemplo, dos municípios de Faxinal do Soturno (72\%), São João do Polêsine (70\%) e São Pedro do Sul (66\%).

Figura 2 - Produto Interno Bruto per capita dos municípios da Região Central - 2012 


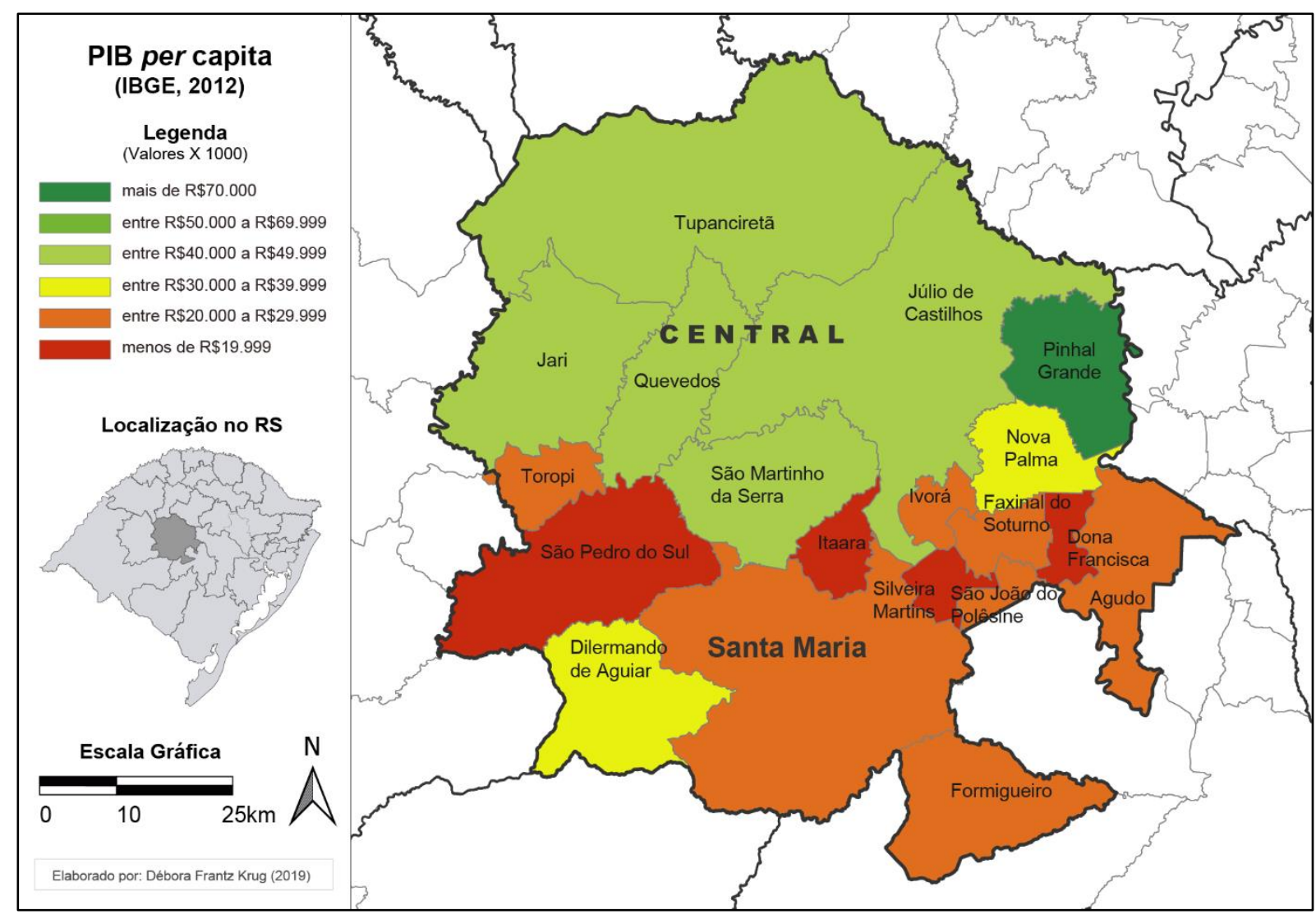

Elaboração: Débora Krug (2019) com base em IBGE (2017).

Também é muito representativo na economia de alguns municípios como Jari (66\%), São Martinho da Serra (59\%), Quevedos (56\%) e Tupanciretã (38\%) os recursos advindos das atividades agropecuárias, reforçando a importância da agricultura familiar, mas também dos cultivos agroindustriais, como é o caso da soja, do trigo e do arroz.

Na cidade de Santa Maria há grande dependência do setor de comércio e de serviços (84\%), com destaque para a presença de redes de atacados, estabelecimentos comerciais e cadeias de supermercado. Também merece destaque os serviços públicos de educação e saúde, e administrativos vinculados aos governos estadual e federal, que a cidade sedia.

Em relação a distribuição do número de empresas na região, observa-se no Gráfico 1, que em 2014, Santa Maria respondia por 5.929 empresas, representando 68,78\% do total das empresas existentes na região. Em segundo e terceiro lugar, aparecem Tupanciretã, com 537 empresas (6,22\%) e a Júlio de Castilhos, com 532 empresas (6,17\%). Os dados explicitam a supremacia e a forte centralidade da economia urbana de Santa Maria na região (IBGE, 2018).

Gráfico 1 - Número de empresas nos municípios da Região Central - 2018 


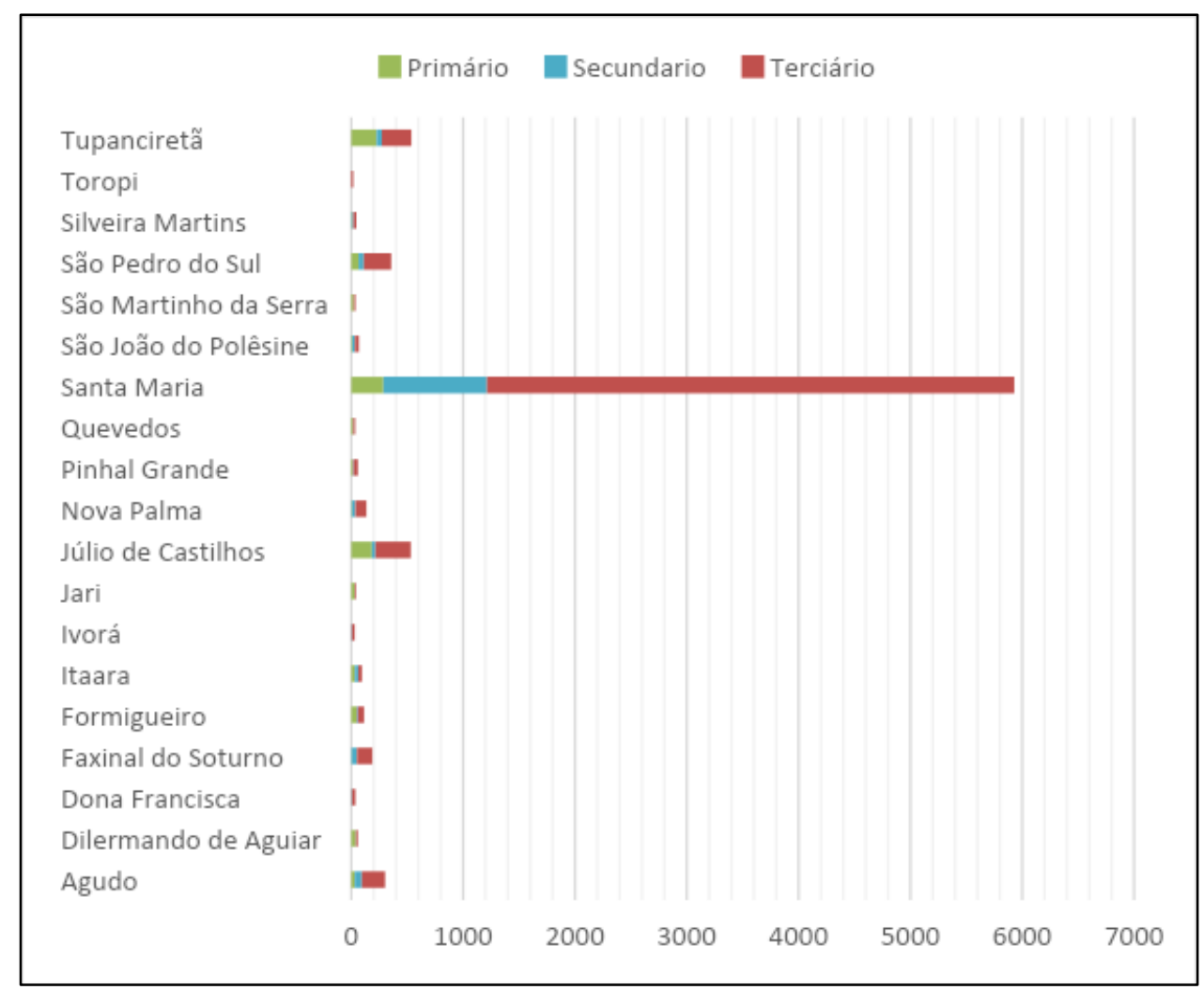

Elaboração: Carolina Faccin, a partir de IBGE (2018).

Quanto aos indicadores sociais existentes nos municípios da região Central verificamos que em relação ao IDH-M, levantado pelo PNUD em 2010, o desempenho é diferenciado, mas sem muita variação no território regional. Analisando o índice de desenvolvimento humano dos municípios, podemos identificar na região dois grupos de municípios. Em um primeiro grupo relativo aos municípios com alto IDHM $(0,700$ a 0,799) verificamos a presença de 10 municípios, com destaque para Santa Maria $(0,789)$, Itaara $(0,760)$ e São João do Polêsine $(0,748)$ que apresentam os maiores índices. Um segundo grupo, relativo aos municípios com médio IDHM $(0,600$ a 0,699) reúne 09 municípios, entre os quais os índices menores são os dos municípios de Jari (0,631), Dilermando Aguiar (0,648) e São Martinho da Serra (0,652) (PNUD, 2010).

\section{A área urbana funcional de Santa Maria}

$\mathrm{Na}$ identificação de áreas urbanas funcionais (FUAs) no território regional, inicialmente considerou-se como referência e ponto de corte os fluxos de deslocamentos para trabalho somados aos fluxos pendulares para estudo entre os municípios da região Central, que alcançassem ao menos o percentual de $10 \%$ da População Economicamente Ativa (PEA) do município de origem, que se destinam para cidades de pelo menos 15 mil habitantes. A 
delimitação do percentual mínimo de $10 \%$ da PEA segue o parâmetro usado pelo IBGE em seu estudo sobre os Arranjos populacionais e Concentrações Urbanas do Brasil (IBGE, 2015).

Posteriormente, com base nesse levantamento inicial, e visando ter uma ideia mais geral de como se apresentam também os fluxos pendulares com menores intensidades no interior da região, organizamos na Tabela 3, os microdados do Censo Demográfico de 2010 do IBGE, sobre deslocamentos pendulares para trabalho e estudo, ampliando o ponto de corte para acima de $4 \%$ da PEA. Com base nesses dados, podemos então identificar nesse território regional a existência da FUA de Santa Maria (IBGE, 2010).

Tabela 3 - Municípios de origem e de destino dos deslocamentos pendulares, e \% da PEA que se deslocam para trabalho e para estudo em Santa Maria - 2010

\begin{tabular}{l|c}
\cline { 2 - 2 } & \multicolumn{1}{c}{ Municípios de destino } \\
\hline Municípios de origem & Santa Maria \\
\hline Dilermando de Aguiar & $6,62 \%$ \\
\hline Dona Francisca & $7,81 \%$ \\
\hline Faxinal do Soturno & $9,38 \%$ \\
\hline Formigueiro & $10,30 \%$ \\
\hline Itaara & $31,84 \%$ \\
\hline Ivorá & $9,91 \%$ \\
\hline Júlio de Castilhos & $4,07 \%$ \\
\hline Nova Palma & $8,00 \%$ \\
\hline São João do Polêsine & $10,39 \%$ \\
\hline São Martinho da Serra & $10,88 \%$ \\
\hline São Pedro do Sul & $8,03 \%$ \\
\cline { 2 - 2 } Silveira Martins & $12,05 \%$ \\
\hline Elaboração: Nicolas Billig de Giacometti (2019) com base em IBGE (2010).
\end{tabular}

Observa-se assim que são definidores para a constituição da FUA de Santa Maria os fluxos pendulares para trabalho e estudo, com destino para a cidade de Santa Maria que se apresentavam acima de $10 \%$ da PEA nos municípios de onde esses fluxos se originaram, em 2010. A saber: Itaara (31,84\%), Silveira Martins (12,05\%), São Martinho da Serra (10,88\%), São João do Polêsine (10,39\%) e Formigueiro (10,30\%). Também levamos em conta para essa definição da FUA de Santa Maria o desempenho apresentado pelos municípios de Ivorá $(9,91 \%)$ e de Faxinal do Soturno $(9,38 \%)$, que embora tenham apresentado fluxos com percentuais abaixo de $10 \%$ das suas PEA, localizam-se próximos à Santa Maria e mantêm importante interação econômica com essa cidade (IBGE, 2010).

A fim de melhor representar espacialmente os deslocamentos pendulares na região Central, apresentamos na Figura 3 um mapa com a espacialização dos fluxos dos deslocamentos 
pendulares para trabalho e estudo entre os municípios e cidades da região, informados na Tabela 3.

Figura 3 - Deslocamentos pendulares da População Economicamente Ativa (PEA) para trabalho e estudo entre os municípios da Região Central - RS - 2010

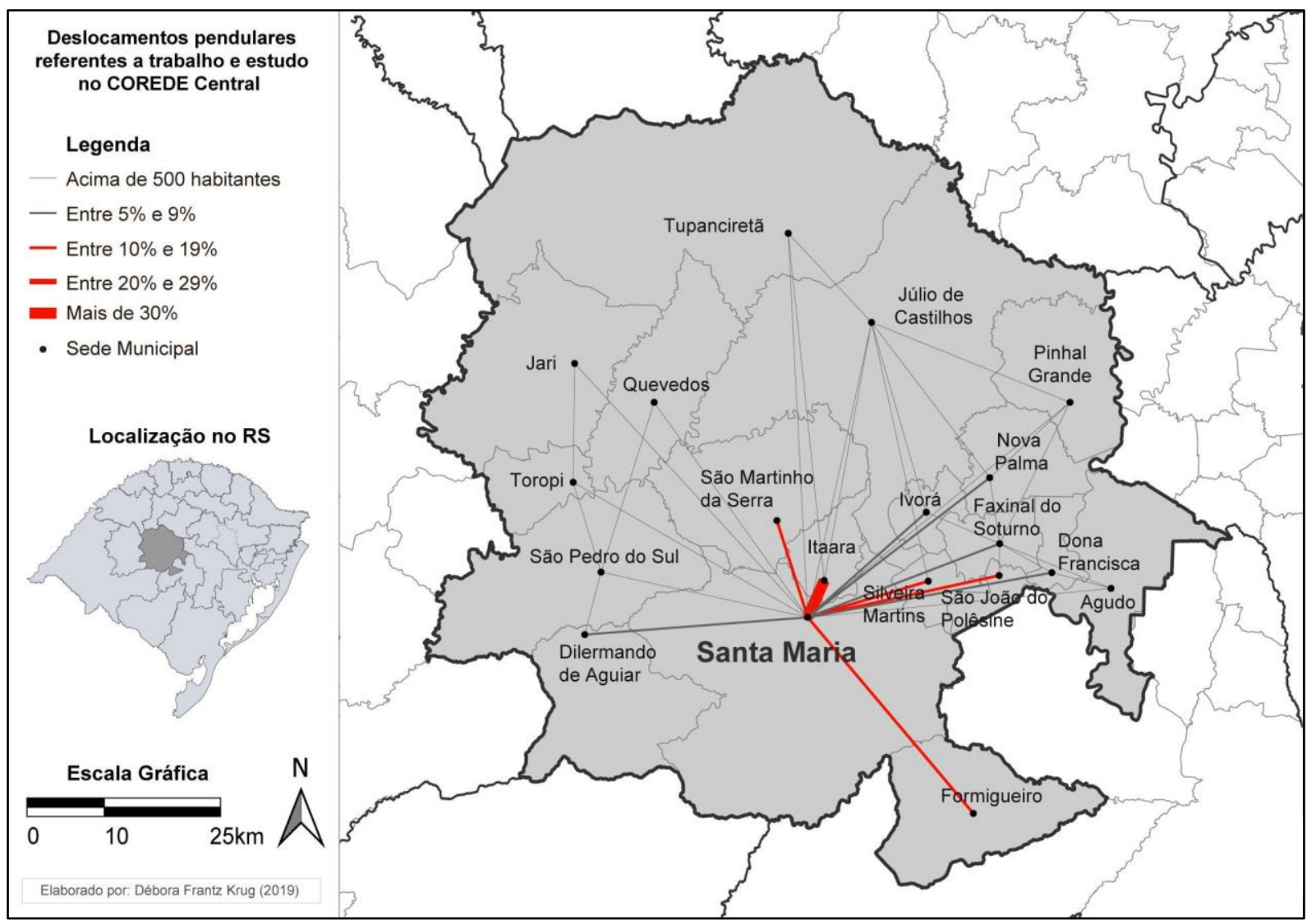

Elaboração: Débora Frantz Krug (2019) com base em IBGE (2010).

Dessa forma, com base nos microdados demográficos do IBGE (2010), identificamos a existência da FUA de Santa Maria na região Central, que é constituída pela cidade de Santa Maria como núcleo central e pelas cidades de Itaara, Silveira Martins, São Martinho da Serra, São João do Polêsine, Formigueiro, Ivorá e Faxinal do Soturno, e suas áreas rurais adjacentes.

A Figura 4 ilustra bem a configuração espacial da FUA de Santa Maria. Destaca-se as áreas mais densamente povoadas, ou seja, aquelas com maior densidade demográfica, representadas por pixels de $1 \mathrm{~km}^{2}$, através de dados obtidos da Grade Estatística (IBGE, 2016) e do Censo Demográfico (IBGE, 2010). Essas áreas correspondem aos núcleos urbanos das cidades. Bem como, também se destacam os territórios dos municípios, sobre os quais a cidade de Santa Maria exerce sua influência e atração, em relação aos fluxos pendulares com deslocamentos para trabalho e estudo. Observa-se igualmente a importância da rede viária que, através da sua 
tipologia e configuração espacial, possibilita as condições de acessibilidade para essas relações funcionais e interações espaciais ocorrerem entre as cidades, e entre elas e as áreas rurais localizadas em seu entorno.

Figura 4 - A FUA de Santa Maria - RS

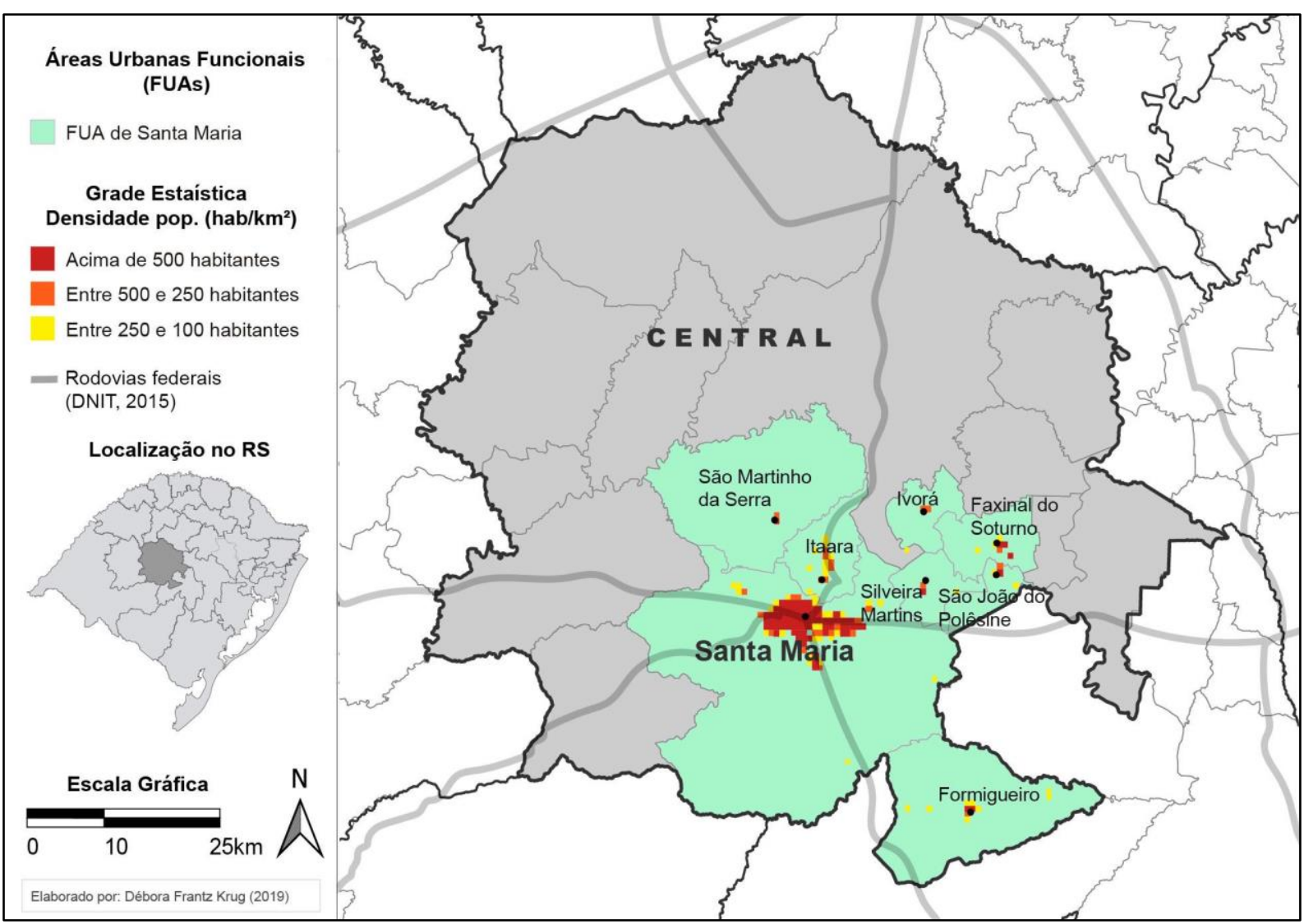

Elaboração: Débora Frantz Krug (2019) com base em IBGE (2010).

A FUA de Santa Maria apresentava em 2010, uma população total de 290.168 habitantes e uma população urbana de 263.351 habitantes, que representavam $47 \%$ da população urbana e $36 \%$ da população total, da região Central (IBGE, 2010).

A estrutura relacional da FUA de Santa Maria apresenta fluxos preponderantemente mono direcionais, pois os fluxos pendulares mais intensos são aqueles que se destinam para a cidade média de Santa Maria desde as demais cidades e áreas rurais do seu entorno. Santa Maria se caracteriza como importante polo regional concentrando a oferta da maior parte dos empregos nos setores da indústria (com destaque para os ramos de máquinas e implementos agrícolas, rações, refrigerantes, materiais de construção, equipamentos de energia e telecomunicações) e, principalmente, nos de comércio e serviços existentes na região (cujos principais ramos de atividade instalados nesta cidade média, são logística, transportes, veículos, 
materiais de construção, atacado e varejo de alimentos, educação, saúde, administração pública e defesa).

A acessibilidade e a proximidade espacial entre os municípios e cidades de onde os fluxos se originam e a cidade de Santa Maria, que é o centro dessa FUA, são também variáveis relevantes que explicam essa dinâmica espacial no interior do território regional. Os demais fluxos pendulares entre as demais cidades da região são pouco expressivos no conjunto dos fluxos pendulares intrarregionais. A baixa circulação de fluxos pendulares para trabalho entre as demais cidades das FUAs se deve a limitada divisão territorial do trabalho existente na região, advinda da especialização das atividades agroindustriais do arroz, do trigo e da soja. Esta última, apresentando intensa integração e dependência do mercado global.

\section{Fluxos pendulares para trabalho na FUA de Santa Maria: características e dinâmica territorial}

Os fluxos pendulares para trabalho entre os municípios da FUA de Santa Maria apresentam intensidades e conteúdos diferenciados também em relação aos setores econômicos do emprego nos locais de destino. A Tabela 4 e a Figura 5 ilustram bem essa distribuição no território regional, destacando os fluxos de pendularidade para o trabalho que tem como destino a cidade média de Santa Maria.

Tabela 4 - Percentual referente à população que se desloca para trabalho em Santa Maria por setor de atividade

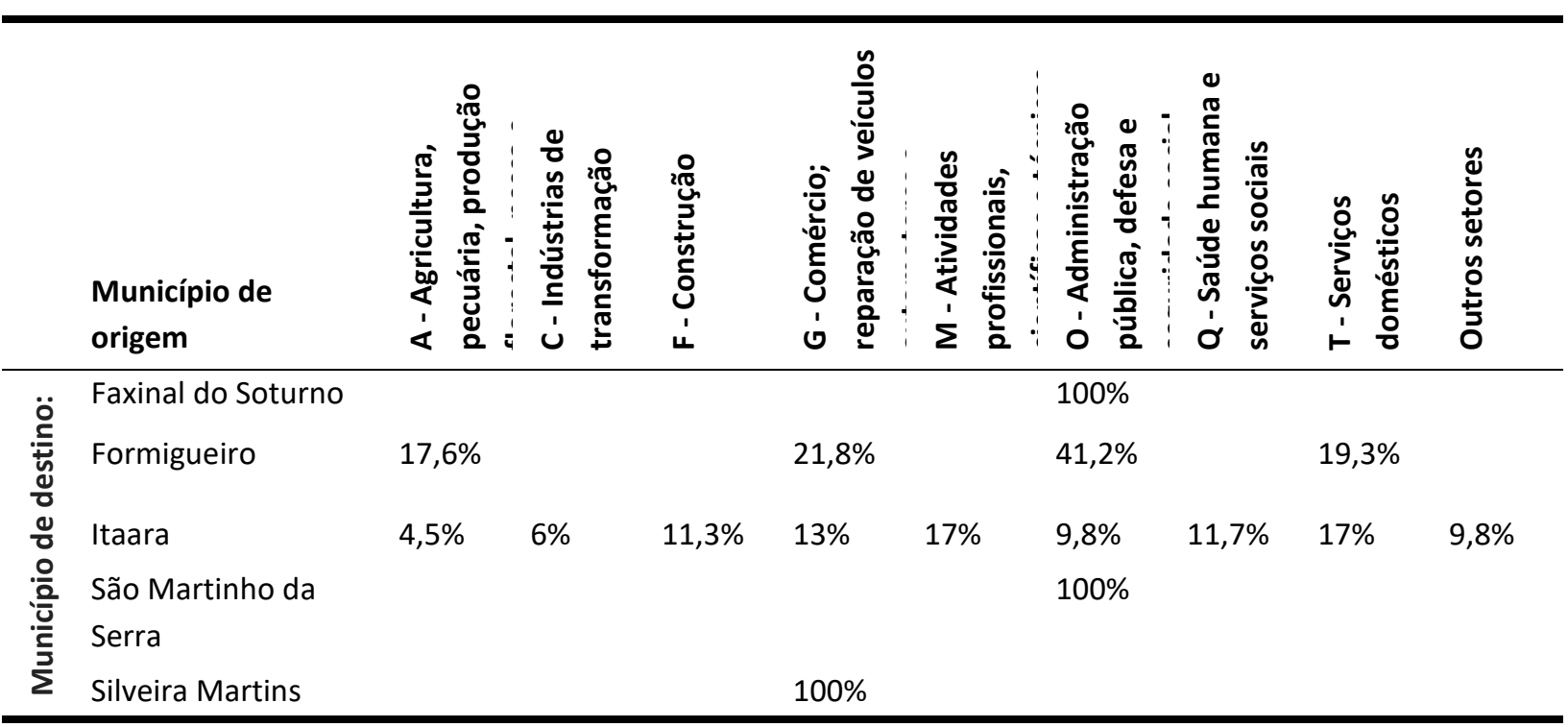

Elaboração: Nicolas Billig De Giacometti com base em Censo IBGE/Dados da amostra (2010). 
Na Figura 5, observamos a configuração espacial dos fluxos pendulares para trabalho nos setores da agropecuária, indústria de transformação e construção civil. Verificamos que o principal local de origem dos trabalhadores que se deslocam para trabalhar no setor agropecuário é o município de Formigueiro, com 17\%, seguido do município de Itaara, com 4,5\%. De acordo com dados da RAIS (2018) as principais empresas agropecuárias desse setor, notadamente as que atuam na produção de arroz e soja, são o principal destino desses trabalhadores. Outro grupo de empresas desse setor é o relacionado à mineração, especialmente relacionada à extração de areia, no município de Itaara.

Já os fluxos pendulares para trabalho nos setores da indústria de transformação e da construção civil, advém do município de Itaara, com respectivamente $6 \%$ e $11,3 \%$. A pequena distância (15 km) e boa acessibilidade viária existente entre as cidades de Itaara e Santa Maria, contribuem para esse deslocamento pendular. Embora a cidade de Santa Maria não tenha no setor industrial o seu esteio, (11,80\% do PIB municipal, e 10\% do emprego, em 2016), esse setor atrai também trabalhadores pendulares da região. Entre os ramos industriais, destacam-se os vinculados à metalurgia, à produção de cimento e artefatos de concreto, e à produção de bebidas e alimentos (AGÊNCIA DE DESENVOLVIMENTO DE SANTA MARIA, 2017; ECONODATA, 2018).

Figura 5 - Deslocamentos pendulares para trabalho na FUA de Santa Maria conforme setor de atividade de ocupação do trabalho - 2010 


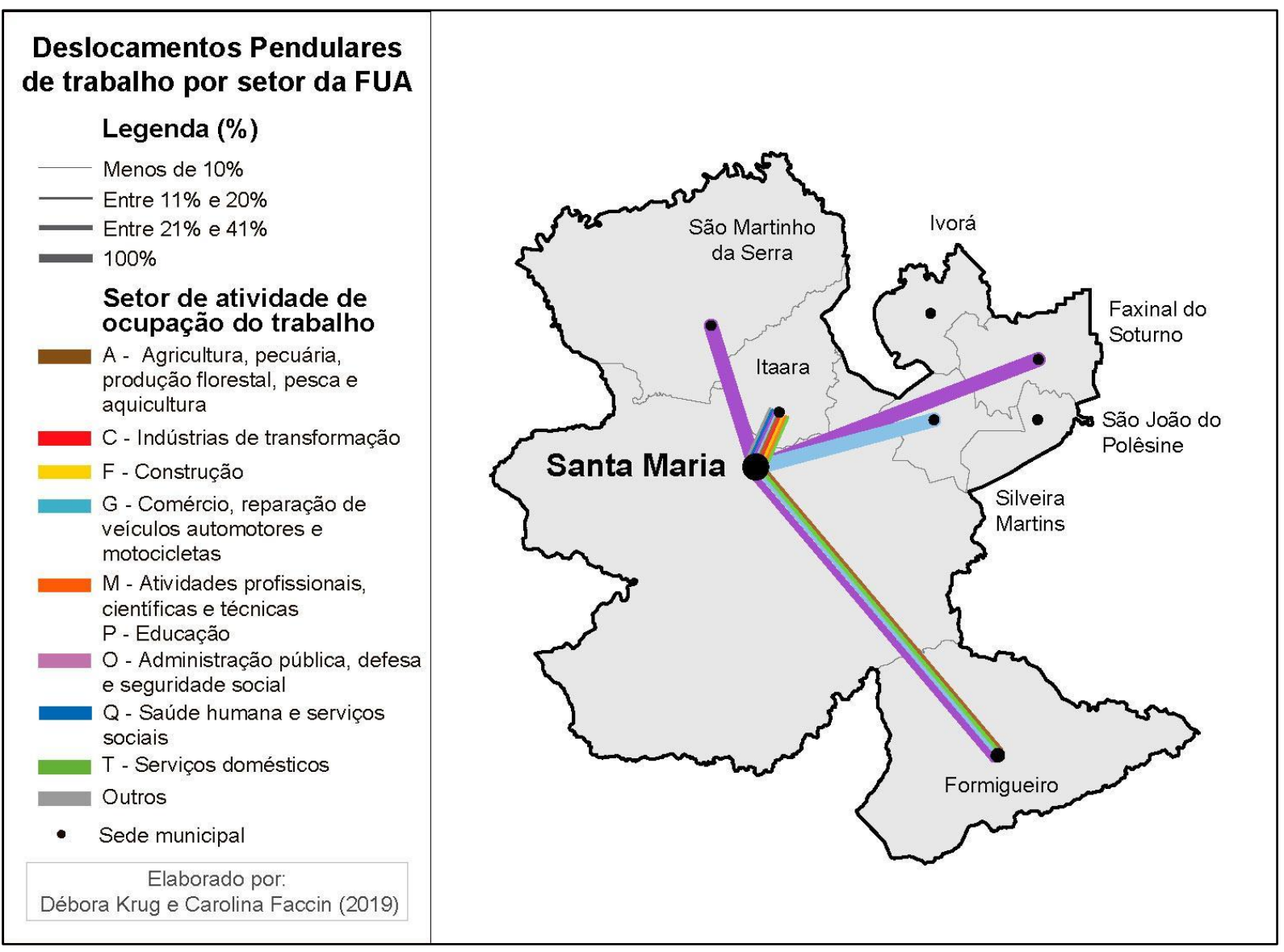

Elaboração: Débora Krug e Carolina Faccin (2019) com base em IBGE (2010).

O intenso processo de urbanização que a cidade de Santa Maria tem apresentado igualmente reflete na dinâmica da indústria da construção civil, notadamente neste período de 2010, com a realização dos projetos habitacionais do Programa Minha Casa Minha Vida, mas também dos projetos de incorporação imobiliária e construção de novos loteamentos e condomínios fechados na cidade. Tal dinâmica tem demandado crescente mão de obra para esse setor, oportunizando emprego para os trabalhadores dos municípios vizinhos, como é o caso de Itaara.

No setor de comércio e reparação de automóveis e veículos automotores, se destacam os fluxos de deslocamento para trabalho originados dos municípios de Silveira Martins, Formigueiro e Itaara, com respectivamente $100 \%, 21,8 \%$ e $13 \%$ do total dos trabalhadores pendulares desses municípios. A condição de polo regional de Santa Maria, se expressa nesse setor, não apenas pela presença de concessionárias das tradicionais marcas de veículos comercializados no país, mas também pela existência de empresas de compra e revenda de automóveis usados, atraindo não só consumidores, mas também trabalhadores com diferentes níveis de especialização do conjunto da região. 
Os principais fluxos pendulares de trabalhadores para a cidade de Santa Maria sem dúvida estão relacionados ao setor de Administração Pública, Defesa e Seguridade Social. Nesse setor, a existência na cidade de Santa Maria de inúmeras sedes regionais de órgãos públicos e autarquias federais e estaduais ligadas à agricultura, à justiça, à Receita Federal, Seguridade, além da presença de inúmeras estruturas militares das forças armadas (quartéis do exército e base aérea da aeronáutica) dão a ela grande centralidade regional em relação à prestação desses serviços, mas também atraem fluxos importantes de trabalhadores pendulares dos municípios e cidades da região. Assim, destacam-se os fluxos pendulares originados dos municípios de Faxinal do Soturno (100\%), São Martinho da Serra (100\%), Formigueiro $(41,2 \%)$ e Itaara $(9,8 \%)$.

Um outro fluxo de trabalho pendular é o que ocorre para o Setor de Saúde Humana e Serviços Sociais, e igualmente revela a centralidade e atração de trabalhadores para atuarem nos serviços de saúde pública e assistência social, nos estabelecimentos que prestam serviço não apenas para a população municipal, mas também para a região. Os hospitais e clínicas de saúde existentes na cidade de Santa Maria oferecem serviços básicos e especializados de atendimento à saúde. Dentre os municípios de onde originam-se fluxos pendulares para esse setor, destacase o de Itaara com $11,7 \%$ dos fluxos para trabalho do município.

Por fim, também cabe destacar dois outros setores para os quais provêm fluxos pendulares para Santa Maria, também originados do município de Itaara. Um primeiro é o Setor de Atividades Científicas e Educação, que apresenta atividades ligadas à oferta do ensino superior e ensino médio. Temos em Santa Maria a existência de inúmeras Faculdades e Universidades, com destaque para a Universidade Federal de Santa Maria que em seus 267 cursos ofertados reúne 28.746 mil alunos, atendidos por 2.047 docentes e 2.668 técnicos administrativos (UFSM, 2020). A proximidade espacial com Itaara contribui para que se tivesse em 2010, um fluxo de $17 \%$ dos trabalhadores pendulares daquele município que atuavam nesse setor. Um segundo setor que também apresenta dados significativos de pendularidade para trabalho com destino para Santa Maria é o de Serviços Domésticos, com trabalhadores pendulares provindos de dois municípios próximos: Itaara (17\%) e de Formigueiro (19,3\%). Tal fluxo revela o movimento de trabalhadores que buscam garantir sua reprodução social, se deslocando para trabalhar, como empregados domésticos e diaristas, nas residências e estabelecimentos comerciais e de serviços da cidade.

\section{Considerações Finais}


O uso do policentrismo e do conceito de área urbana funcional como recursos metodológicos nos estudos urbanos e regionais sobre a dinâmica do desenvolvimento territorial nos ofereceu a possibilidade de analisar os dados secundários sobre deslocamento pendular para trabalho e estudo na Região Central do estado do Rio Grande do Sul. O estudo, ainda que com resultados preliminares, mostrou a importância que fluxos pendulares para trabalho adquirem para a análise e a compreensão da configuração, organização e funcionamento da rede urbana regional bem como para melhor apreender os processos e relações socioespaciais que caracterizam a dinâmica territorial regional.

Verificamos o papel de comando da cidade de Santa Maria na configuração espacial e dinâmica territorial da região Central. A centralidade da economia urbana diversificada da cidade média de Santa Maria atrai os fluxos pendulares para trabalho e estudo dos municípios e respectivos núcleos urbanos secundários, que constituem essa região de planejamento, mas também atraem, em menor intensidade, os fluxos pendulares dos demais lugares que constituem essa região, localizada no centro do Rio Grande do Sul.

Observa-se no conjunto do território regional a constituição de uma rede urbana simples, condicionada pela incipiente divisão territorial do trabalho que caracteriza a dinâmica de funcionamento dos setores agroindustriais da soja, do trigo e do arroz, com fluxos pendulares muito desiguais no território. Os fluxos mais dinâmicos e intensos, têm se concentrado sobretudo na parte central do território regional, onde a cidade média e centro de comando regional de Santa Maria está localizada, reforçando a sua importância na rede urbana regional.

Os resultados desse estudo, baseados sobretudo na análise dos fluxos pendulares, contudo, ainda não nos permitem compreender em profundidade a dinâmica territorial regional e a organização e funcionamento da rede urbana regional, que a cidade de Santa Maria centraliza e polariza. Para tanto, ainda falta concluir os demais estudos sobre os demais fluxos que circulam no interior da região, como os fluxos de capital, de mercadorias, insumos e informações.

Por fim, pensamos que o uso metodológico da identificação e análise da densidade e conteúdo dos fluxos pendulares para trabalho são relevantes para que se possa melhor compreender a dinâmica territorial e pensar estratégias de desenvolvimento na escala regional, ou mesmo auxiliar para qualificar políticas de intervenção integradas que não coincidam com as delimitações político administrativas tradicionais, como verificadas na escala municipal ou estadual. 


\section{Referências}

ANTIKAINEN, J. The concept of Functional Urban Area: Findings of the ESPON Project 1.1.1. Informationen zur Raumentwicklung. 7(1), 447-452, 2005.

BRENNER, N. Espaços da urbanização: o urbano a partir da teoria crítica. 1. ed. - Rio de Janeiro: Letra Capital: Observatório das Metrópoles, 2018.

CATTAN, N. (Org.). Cities and networks in Europe: a critical approach of polycentrism. Montrouge: John Libbey Eurotext, 2007.

DAVOUDI, S. Polycentricity: Panacea or pipedream? In: Cattan, N. (Ed.) Cities and networks in Europe. (p. 65-73). Montrouge: John Libbey Eurotext, 2007.

. Polycentricity in European Spatial Planning: From na Analytical Tool to a Normative Agenda. European Planning Studies, 11(8), 979-999, 2003.

HALL, P. Delineating urban territories: Is this a relevant issue? In: Cattan, N. (Ed.) Cities and networks in Europe. (p. 03-14). Montrouge: John Libbey Eurotext, 2007.

INSTITUTO BRASILEIRO DE GEOGRAFIA E ESTATÍSTICA - IBGE. Censo demográfico. Rio de Janeiro: IBGE, 2000. Disponível em: <https://biblioteca.ibge.gov.br/index.php/bibliotecacatalogo?view=detalhes\&id=783>. Acesso em 06 jun. 2020.

Região de Influência das Cidades - REGIC 2007. Rio de Janeiro, IBGE, 2008. Disponível em: <https://www.ibge.gov.br/geociencias/cartas-e-mapas/redes-geograficas/15798-regioesde-influencia-das-cidades.html>. Acesso em 06 jun. 2020.

Censo demográfico. Rio de Janeiro: IBGE, 2010. Disponível em:

<https://censo2010.ibge.gov.br/resultados.html>. Acesso em 06 jun. 2020.

Arranjos populacionais e Concentrações Urbanas do Brasil. Rio de Janeiro: IBGE, 2015. Disponível em: <https://www.ibge.gov.br/apps/arranjos populacionais/2015/>. Acesso em 06 jun. 2020.

. Grade estatística. Rio de Janeiro: IBGE, 2016. Disponível em:

<https://mapas.ibge.gov.br/interativos/grade.html>. Acesso em 06 jun. 2020.

Produto Interno Bruto dos Municípios 2002-2017: ano base 2012. Rio de Janeiro: IBGE, 2017. Disponível em: <https://www.ibge.gov.br/estatisticas/economicas/contasnacionais/9088-produto-interno-bruto-dos-municipios.html>. Acesso em 06 jun. 2020.

Pesquisa de Informações Básicas Municipais - MUNIC. Rio de Janeiro: IBGE, 2018. Disponível em: <https://www.ibge.gov.br/estatisticas/sociais/saude/10586-pesquisa-deinformacoes-basicas-municipais.html>. Acesso em 06 jun. 2020.

KARLSSON, C.; OLSSON, M. The identification of functional regions: theory, methods, and applications. Annals of Regional Science, 40(1), 1-18, 2006. 
LLOP, J. M.; USÓN, E. (Org). Ciudades Intermedias. Dimensiones y definiciones. Lleida: Editorial Milenio, 2012.

RELAÇÃO ANUAL DE INFORMAÇÕES SOCIAIS - RAIS. Número de estabelecimentos e número de vínculos por setor do CNAE 2.0 Classe. Brasília: TEM, 2018. Disponível em:

<http://bi.mte.gov.br/bgcaged/caged.php>. Acesso em 06 jun. 2020.

PROGRAMA DAS NAÇÕES UNIDAS PARA O DESENVOLVIMENTO - PNUD. Atlas de

Desenvolvimento Humano nos Municípios. Brasília: PNUD, 2010. Disponível em:

<http://www.atlasbrasil.org.br/2013/pt/radar-idhm/>. Acesso em 06 jun. 2020.

SASSEN, S. Sociologia da Globalização. Porto Alegre: Ed. Artmed, 2010.

SANTOS, MILTON. Por uma outra globalização. São Paulo: Ed. Record, 2000.

SANTOS, MILTON E SILVEIRA, MARIA LAURA. O Brasil: Território e Sociedade no início do Século XXI. Rio de Janeiro: Ed. Record, 2001

SECRETARIA DE PLANEJAMENTO, ORÇAMENTO E GESTÃO - SEPLAG; DEPARTAMENTO DE PLANEJAMENTO GOVERNAMENTAL - DEPLAN. Perfis Socioeconômicos Regiões Funcionais de Planejamento. Porto Alegre: SEPLAG/DEPLAN, 2015. Disponível em:

<https://planejamento.rs.gov.br/upload/arquivos/201512/15134058-20150319163519perfistodos.pdf>. Acesso em 06 jun. 2020.

SECRETARIA DE PLANEJAMENTO, GOVERNANÇA E GESTÃO - SPGG. Plano Estratégico de Desenvolvimento Regional do COREDE Central 2015-2030. Porto Alegre: SPPG, 2017. Disponível em: <https://governanca.rs.gov.br/upload/arquivos/201710/09144203-planocentral.pdf>. Acesso em 06 jun. 2020.

SILVEIRA, R. L. L., BRANDT, G. B., FACCIN, C. R., SILVEIRA, L. L., KUMMER, D. C. Policentrismo, Áreas Urbanas Funcionais (FUAs) e Dinâmica Territorial: Um estudo exploratório desde a região do Vale do Rio Pardo - RS - Brasil. In: Redes, 22(1), 184-217, 2017. Disponível em:

<https://online.unisc.br/seer/index.php/redes/article/view/8641>. Acesso em: 10 mai. 2020.

SPÓSITO, M. E. B.; SILVA, W. R. Perspectivas da urbanização: Reestruturação urbana e das cidades. Rio de Janeiro: Editora Consequência, 2017.

SÝKORA, L..; MULÍČEK, O. The micro-regional nature of functional urban areas (FUAs): lessons from the analysis of the Czech urban and regional system. Urban Research \& Practice, 2(3), 287-307, 2009.

UNIVERSIDADE FEDERAL DE SANTA MARIA - UFSM. UFSM em números: dados referentes ao período 10 Semestre de 2020. Disponível em: <https://portal.ufsm.br/ufsm-em-

numeros/publico/index.html>. Acesso em 06 jun. 2020. 